\title{
DIRECT VERSUS TERMINAL ROUTING ON A MARITIME HUB-AND-SPOKE CONTAINER NETWORK
}

Chaug-Ing Hsu

Professor, corresponding author, Department of Transportation Technology and Management, National Chiao Tung University, 1001 Ta Hsueh Road, Hsinchu, Taiwan 300, R.O.C, cihsu@cc.nctu.edu.tw

Yu-Ping Hsieh

Ph.D. Candidate, Department of Transportation Technology and Management, National Chiao Tung University; Associate Researcher, Center of Harbor \& Marine Technology, Institute of Transportation, 2 Chung-Heng 10th Road, Wuchi, Taichung, Taiwan 435, R.O.C

Follow this and additional works at: https://jmstt.ntou.edu.tw/journal

Part of the Business Commons

\section{Recommended Citation}

Hsu, Chaug-Ing and Hsieh, Yu-Ping (2005) "DIRECT VERSUS TERMINAL ROUTING ON A MARITIME HUB-AND-SPOKE CONTAINER NETWORK," Journal of Marine Science and Technology. Vol. 13: Iss. 3, Article 7.

DOI: $10.51400 / 2709-6998.2128$

Available at: https://jmstt.ntou.edu.tw/journal/vol13/iss3/7

This Research Article is brought to you for free and open access by Journal of Marine Science and Technology. It has been accepted for inclusion in Journal of Marine Science and Technology by an authorized editor of Journal of Marine Science and Technology. 


\title{
DIRECT VERSUS TERMINAL ROUTING ON A MARITIME HUB-AND-SPOKE CONTAINER NETWORK
}

\author{
Chaug-Ing Hsu* and Yu-Ping Hsieh**
}

Key words: routing decision, hub-and-spoke networks, multi-objective analysis.

\section{ABSTRACT}

This study formulates a two-objective model by individually minimizing shipping costs and inventory costs to decide whether to route a shipment through a hub or directly to its destination. First, shipping and inventory cost functions are formulated for a multi-port calling route. Shipping costs include capital and operating cost, fuel cost and port charge, while inventory costs include waiting time cost and shipping time cost. Then, based on a trade-off between shipping costs and inventory costs for two types of shipping routes, Pareto optimal solutions of the two-objective model are determined, and a routing decision can be illustrated and made in objective value space. The optimal routing, ship size and sailings frequency with respect to each level of inventory cost is shown. The results show that the optimal decision tends to be direct shipping as container flow between origin and destination ports increases.

\section{INTRODUCTION}

Container carriers operate in an increasingly competitive and market-driven environment. Most of them continuously provide their services using hub-and-spoke networks. Under a hub-and-spoke network, economies of flow can be realized by consolidating freight through a hub and using large ships. However, routing all freight through a hub is not necessarily appropriate in any situations. Although the average shipping cost per TEU decreases on line-haul legs of hub-and-spoke networks, freight originated in feeder ports must be transshipped through a hub, and incur extra shipping distance, shipping time, port charges and stevedoring

Paper Submitted 11/08/04, Accepted 04/22/05. Author for Correspondence: Chaug-Ing Hsu. E-mail: cihsu@cc.nctu.edu.tw.

*Professor, corresponding author, Department of Transportation Technology and Management, National Chiao Tung University, 1001 Ta Hsueh Road, Hsinchu, Taiwan 300, R.O.C.

**Ph.D. Candidate, Department of Transportation Technology and Management, National Chiao Tung University; Associate Researcher, Center of Harbor \& Marine Technology, Institute of Transportation, 2 Chung-Heng 10th Road, Wuchi, Taichung, Taiwan 435, R.O.C. charges. Therefore, container carriers must decide whether to route a shipment through a hub or directly to its destination. This study constructs an analytical model on exploring this issue.

Previous studies on maritime shipping service planning such as ship routing, fleet deployment, and ship scheduling were focused largely on general networks (e.g., Rana and Vickson [15]; Cho and Perakis [3]; Powell and Perakis [14]; Sambracos et al. [19]; Ronen $[17,18]$ etc.), while studies about hub-and-spoke networks were few. However, as hub-and-spoke networks have been used by more container carriers recently, more and more studies discuss about these special networks (e.g., Robison [16]; Bendall and Stent [1]; Mourão et al. [13]; Hsieh and Chang [9] etc.). Some of them proposed employing constraints to deal with the characteristics of transshipment in hub-and-spoke networks, and some of them introduced cost discount on main-line shipping to deal with flow economies. However, differing from previous studies, this study formulates flowdependent cost functions and constructs a two-objective model by individually minimizing shipping costs and inventory costs to analyze routing decision on providing shipping services in a hub-and-spoke network.

Container carriers concern both shipping costs and inventory costs when they make routing decisions, because they not only aims at lowering their shipping costs but also enhancing their services to attract more shippers. Inventory costs are considered to be crucial factors affecting the shippers' demand. So both inventory cost and shipping cost are regarded as decision factors. Inventory cost is commonly regarded as a major factor affecting shipping service decision in logistics literature. These studies usually determined the optimal shipping frequency by minimizing total shipping and inventory costs (e.g., Daganzo [5]; Hall [7] etc.). In maritime study, Jansson and Shneerson [11] also proposed an economic model to analyze shipping service decision by minimizing total shipping and inventory costs. However, in reality, although container carriers consider inventory cost as a decision factor, the weight 
placed on inventory cost is usually not equal to that on shipping cost. Therefore, the model proposed herein regards shipping costs and inventory costs as two separate objectives. The optimal routing with respect to each level of inventory cost and shipping cost can be determined using the proposed model. In addition, the proposed two-objective model not only provides flexibility for container carriers in routing decision-making, but also provides a tool to analyze the trade-off between shipping cost and inventory cost. Furthermore, singleobjective decision-making by minimizing total shipping and inventory costs or merely minimizing shipping cost could be regarded as a special case of the twoobjective decision.

In this study, a hub-and-spoke maritime network is considered to provide freight shipping services between two continents or regions separated by a major ocean. In each region, one or several ports are selected as hub ports based on location and freight shipping demands. Then, large mother ships are used to provide services among hub ports in different regions, and small feeder ships are used to provide services between hub port and its spoke (or feeder) ports in the same region. A fundamental hub-and-spoke maritime network considered in this study is shown in Figure 1. This study explores route decision-making on whether freight between feeder ports on one feeder line at origin region (e. g., ports $p 1$ and $p 2$ ) and hub ports at destination region (e.g., ports $p 5$ and $p 6$ ) should be shipped directly (i.e., shipped by the direct line, $d: p 1, p 2, p 5, p 6, p 5, p 1)$ or shipped through the local hub port at origin region (i.e., shipped via hub port, $p 3$, by routing the feeder line, $s$ : $p 1, p 2, p 3, p 1$, and then the main line, $h: p 3, p 4, p 5, p 6$, $p 5, p 4, p 3)$.

The remainder of this study is organized as follows. In Section 2, shipping and inventory cost functions are formulated by analyzing shipping process for a containership serving a multi-port calling route. Section 3 determines Pareto optimal solutions of the two-objective model based on a trade-off between shipping costs and inventory costs. Section 4 presents an example that

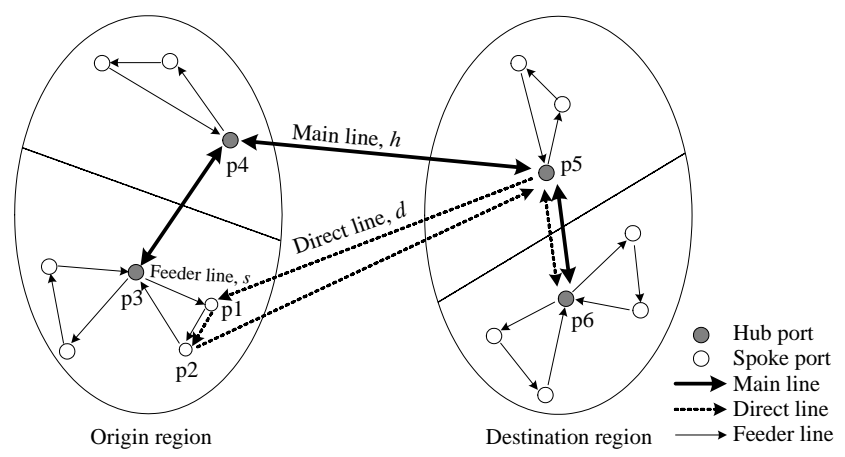

Fig. 1. The fundamental hub-and-spoke maritime network. demonstrates the usefulness of the proposed model. Concluding remarks are finally made in Section 5.

\section{COST FUNCTIONS}

Consider a multi-port calling route, $m$, calls at $n^{m}$ ports, where $n^{m} \in N$. The route starts from port 1 , and follows by port 2 , port $3 \ldots$ and port $n^{m}$, and then returns back to port 1 . The ports of call on the route may be different or some of them are routed again on the returning route as shown by Figures 2(a) and 2(b), respectively. On the route, ocean carrier operates $f$ sailings frequency per season using ship type $t$. Ships in this study are containerships with dry cargo containers, and the unit of containers is TEU, i.e. twenty-foot equivalent unit. The cost function herein follows the formulation of Hsu and Hsieh [8]. This section summarizes the cost function proposed by Hsu and Hsieh [8].

Suppose flow from one port to another port on the route is given. Let $Q_{i j}^{m}$ denote flow from port $i$ to port $j$ on route $m$ per season, where $i, j=1,2 \ldots n^{m}$ and $Q_{i j}^{m}$ $=0$ for $i=j$. Then the loading and unloading volumes in any port $i$ per round voyage are $\frac{1}{f} \sum_{j} Q_{i j}^{m}$ and $\frac{1}{f} \sum_{j} Q_{i j}^{m}$, respectively.

Shipping costs can be divided into three main categories: Capital and operating cost, fuel cost and port charge. Capital and operating cost represents the total expenses paid for using the ship each day, including the cost of owning the ship, crew wages and meals, ship repair and maintenance, insurances, materiel and supplies, diesel oil consumption, and so on. Capital and operating cost increases with ship size, operating time and sailings frequency.

The total shipping time per round voyage for a ship includes line-haul time at sea and dwelling time in port. The port dwelling time include the cargo loading and unloading time and the arrival and departure process time that a ship spends at ports. The cargo loading and unloading time can be estimated by container loading/unloading volume and the handling rate. Let $R_{i}$ denote the average gross handling rate, TEU per day, in port $i$, then the cargo loading and unloading time in any port $i$ is $\frac{1}{f R_{i}} \sum_{j}\left(Q_{i j}^{m}+Q_{j i}^{m}\right)$. The arrival and

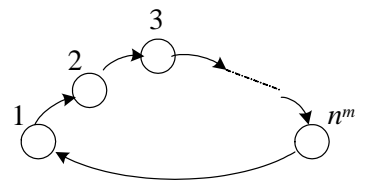

(a)

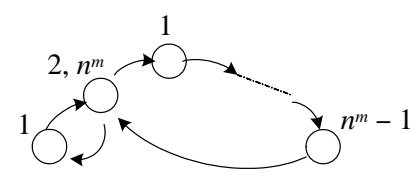

(b)
Fig. 2. Shipping routes: (a) all ports of call are different; (b) some of ports are repeated. 
departure process time includes not only time a ship moving into or out from the port but also time a ship waiting for entering or leaving a port. The length of time can be estimated by the average ship waiting time and the average ship sailing time in a port. Let $W_{i}$ denote port arrival and departure process time in any port $i$, and the unit of time is day. Then, time a ship spending in any port $i$ is $W_{i}+\frac{1}{f R_{i}} \sum_{j}\left(Q_{i j}^{m}+Q_{j i}^{m}\right)$. Moreover, the total time that a ship spends on all ports per round voyage is the sum of the dwelling time of $n^{m}$ ports, i.e. $\sum_{i} W_{i}+\frac{1}{f R_{i}} \sum_{i} \sum_{j}\left(\frac{Q_{i j}^{m}+Q_{j i}^{m}}{R_{i}}\right)$.

Let $D_{i}^{m}$ denote shipping distance between any consecutive port $i$ and port $i+1$ on route $m$, and $V_{t}$ denote average service speed for ship type $t$. Then, shipping time at sea per round voyage is $\frac{1}{V_{t}} \sum_{i} D_{i}^{m}$, and the total shipping time per round voyage is the sum of time spent in all ports and at sea, i.e. $\sum_{i}\left(W_{i}+\frac{D_{i}^{m}}{V_{t}}\right)$ $+\frac{1}{f} \sum_{i} \sum_{j}\left(\frac{Q_{i j}^{m}+Q_{j i}^{m}}{R_{i}}\right)$. Furthermore, let $S_{t}$ denote average daily capital and operating cost for ship type $t$. Then, the total capital and operating cost for a season with $f$ sailings frequency is

$$
f S_{t} \sum_{i}\left(W_{i}+\frac{D_{i}^{m}}{V_{t}}\right)+S_{t} \sum_{i} \sum_{j}\left(\frac{Q_{i j}^{m}+Q_{j i}^{m}}{R_{i}}\right) .
$$

Fuel cost is the expense of fuel consumption by a ship sailing at sea and dwelling in port. Fuel cost increases with ship size either at sea or in port. Moreover, fuel cost at sea is proportional to the shipping distance, since a ship normally cruises at constant speed at sea. Fuel cost in port is different from fuel cost at sea, for a ship must decelerate or accelerate when entering or leaving a port, while it also depends on distance a ship moving in port. If a port area is larger, the relative moving distance may be longer and the fuel cost in port is higher. Therefore, fuel costs for the same ship in various ports are different. Sometimes fuel cost in port can be ignored due to it is relatively small. Let $F_{t}$ denote fuel cost at sea per nautical mile by ship type $t$, and $B_{i t}$ denote fuel cost in port $i$ by ship type $t$. Then, the fuel cost per round voyage on route $\mathrm{m}$ by ship type $t$ is $\sum_{i}\left(F_{t} D_{i}^{m}+B_{i t}\right)$, and the total fuel cost for a season with $f$ sailings frequency is

$$
f \sum_{i}\left(F_{t} D_{i}^{m}+B_{i t}\right) \text {. }
$$

Port charge is paid for a ship dwelling in port and can be divided into charge on ship and stevedoring charge. The former is paid for servicing the ship, including pilotage, towage, line handling fee, and berth occupancy charge, etc. The latter is paid for cargo handling, including container loading and unloading charges, equipment charge, and rent of container yard, etc.

The level and structure of port charge in various ports are different. In usual, port charge of a ship depends on gross tonnage or capacity of a ship and also depends on berth occupancy time, so port charge of a ship increases with ship size and berth occupancy time. However, pilotage, towage, and line handling fee are independent of berth occupancy time, while berth occupancy charge is proportional to berth occupancy time. Let $\alpha_{i t}$ denote portion of port charge of a ship that is independent of berth occupancy time, and $\beta_{i t}$ denote portion of port charge of a ship that is proportional to berth occupancy time, where subscript $i$ and $t$ indicate port $i$ and ship type $t$, respectively. Then, the total port charge on ship serving a route for a season with $f$ sailings frequency is $f \sum_{i} \alpha_{i t}+\sum_{i} \sum_{j} \frac{\beta_{i t}}{R_{i}}\left(Q_{i j}^{m}+Q_{j i}^{m}\right)$. Let $G_{i}$ denote average handling charge per TEU in port $i$. Then, the total stevedoring charge for a season is $\sum_{i} \sum_{j} G_{i}\left(Q_{i j}^{m}+Q_{j i}^{m}\right)$. The total port charge is the sum of the total port charge on ship and the total stevedoring charge. That is

$$
f \sum_{i} \alpha_{i t}+\sum_{i} \sum_{j}\left[\left(\frac{\beta_{i t}}{R_{i}}+G_{i}\right) \cdot\left(Q_{i j}^{m}+Q_{j i}^{m}\right)\right] .
$$

From Eqs. (1)-(3), total shipping cost for a season with $f$ sailings frequency on route $m$ by ship type $t$, $T C 1^{m}$, is the sum of the capital and operating cost, the fuel cost, and the port charge. That is

$$
\begin{aligned}
T C 1^{m} & =f \sum_{i}\left[\alpha_{i t}+S_{t} W_{i}+B_{i t}+D_{i}^{m}\left(\frac{S_{t}}{V_{t}}+F_{t}\right)\right] \\
& +\sum_{i} \sum_{j}\left[\left(G_{i}+\frac{\beta_{i t}}{R_{i}}+\frac{S_{t}}{R_{i}}\right)\left(Q_{i j}^{m}+Q_{j i}^{m}\right)\right]
\end{aligned}
$$

Inventory cost represents opportunity cost or loss of value that cargo cannot be used or sold in the shipping process, and is positively correlated with cargo volume, value of cargo, and length of storage time. In this study, only inventory cost related to container shipping process are taken into account, involving the waiting time cost in the loading port and the shipping time cost that containers are shipped on a ship. However, inventory 
cost that occurred in the destination unloading port is not taken into account because it is not directly related to decisions on the containership shipping routing.

Waiting time cost is the cost related to sailings frequency which result in schedule delay for containers either waiting in the loading port or at the place of production or origin. The higher the sailings frequency is, the lower the waiting cost is. Assuming that the arrival process of containers at each loading port follows a uniform distribution, then the average waiting time per TEU in a loading port is one half of a shipping time cycle. Let $H$ denote the daily value of time per TEU, and suppose one season approximates to 13 weeks or 91 days. The total waiting time cost per season for containers shipped on route $m$ is

$$
\frac{91 H}{2 f} \sum_{i} \sum_{j} Q_{i j}^{m}
$$

Shipping time cost is related to time while containers are shipped on a ship, and increases with the shipping time. Let $T_{i j}^{m}$ denote the shipping time of containers from port $i$ to port $j$ on route $m$. It includes time that a ship spends on routing through all links and ports on the path from port $i$ to port $j$. Since time that containers spend in unloading ports is not easy to estimate and not related to routing decisions, the time that containers spend in loading and unloading ports is approximately estimated as time spent in loading ports only. Therefore, $T_{i j}^{m}$ can be represented as

$$
T_{i j}^{m}=\sum_{k} \delta_{i j k}^{m}\left(W_{k}+\frac{D_{k}^{m}}{V_{t}}\right)+\frac{1}{f} \sum_{k} \sum_{l} \frac{\delta_{i j k}^{m}}{R_{k}}\left(Q_{k l}^{m}+Q_{l k}^{m}\right) .
$$

Where $\delta_{i j k}^{m}$ is defined as

$$
\delta_{i j k}^{m}=\left\{\begin{array}{c}
1, \text { if path from port } i \text { to } j \text { containes a link } \\
\text { between port } k \text { and } k+1 \\
0, \text { otherwises }
\end{array}\right.
$$

The total shipping time cost per season for containers shipped on route $m$ is equal to $H \sum_{i} \sum_{j}\left(Q_{i j}^{m} T_{i j}^{m}\right)$,
and can be expressed further as: $H \sum_{i} \sum_{j} \sum_{k} Q_{i j}^{m} \delta_{i j k}^{m}\left(W_{k}+\frac{D_{k}^{m}}{V_{t}}\right)+\frac{H}{f} \sum_{i} \sum_{j} \sum_{k} \sum_{l} \frac{Q_{i j}^{m} \delta_{i j k}^{m}}{R_{k}}\left(Q_{k l}^{m} Q_{l k}^{m}\right)$.

From Eqs. (5) and (8), the total inventory cost for a season for containers shipped on route $m$ by ship type $t, T C 2^{m}$, is the sum of the total waiting time cost and the total shipping time cost. That is:

$$
\begin{aligned}
T C 2^{m} & =\frac{91 H}{2 f} \sum_{i} \sum_{j} Q_{i j}^{m}+H \sum_{i} \sum_{j} \sum_{k} Q_{i j}^{m} \delta_{i j k}^{m}\left(W_{k}+\frac{D_{k}^{m}}{V_{t}}\right) \\
& +\frac{H}{f} \sum_{i} \sum_{j} \sum_{k} \sum_{l} \frac{Q_{i j}^{m} \delta_{i j k}^{m}}{R_{k}}\left(Q_{k l}^{m}+Q_{l k}^{m}\right) .
\end{aligned}
$$

\section{ROUTING DECISION}

There is a trade-off between shipping cost and inventory cost shown as Eqs. (4) and (9), above. That is, in a higher sailings frequency route, the inventory cost is low and the shipping cost is high, while in a lower sailings frequency route, the shipping cost is low and the inventory cost is high. However, a complete optimal solution does not exist when one objective aimed at minimizing shipping cost while the other objective aimed at minimizing inventory cost due to they conflict with each other. Instead of a complete optimal solution, the Pareto optimality concept is introduced herein. The Pareto optimality is the solution where no objective can be reached without simultaneously worsening at lease one of the remaining objectives. (Cohon [4])

The feasible solutions that minimize two objectives for each type of ship are determined using tradeoff relationship and the constraint of ship capacity. And the Pareto optimal solution can be further determined by comparing the feasible solutions of all types of ships. Moreover, the optimal ship size and sailings frequency yielding the minimum shipping cost with respect to each level of inventory cost can be determined at the same time. In the meantime, the Pareto optimal solutions for decisions on either routing a shipment through a hub or directly to its destination can be determined further in a similar way.

Suppose routing decisions are made by two objectives, i.e. individually minimizing total shipping costs and minimizing total inventory costs of a hub-andspoke network system. When comparing Pareto optimal solutions for routing a shipment through a hub with routing directly to its destination, since the Pareto optimal solutions for containers shipped from spoke ports on one feeder line in origin region to a hub in destination region won't be affected by all other feeder lines, it is not necessary to calculate shipping and inventory costs of all routes in the system. As shown in Figure 1, only costs on three lines, i.e. lines $s, h$, and d, are considered when routing a shipment directly to its destination, while costs on two lines $s$ and $h$ are considered when routing a shipment through a hub.

Since a hub has the advantage of cargoconsolidation, it is assumed cargo flow in a main line is very large. Then, the main line can be serviced with the 
minimum shipping cost, no matter how large the inventory cost is. Let $\overline{T C 1_{t^{*}}^{h}}$ denote the minimum shipping cost in main line, and $\overline{T C 2_{t}^{h}}$ denote the respective inventory cost. Then, the minimum shipping cost results from the optimal sailings frequency which equals to the maximum link flow, $\operatorname{Max}_{k} \sum_{i} \sum_{j} \delta_{i j k}^{h} Q_{i j}^{h}$, divided by the capacity of ships, $U_{t^{*}}$. That is $f=\frac{\operatorname{Max} \sum_{i} \sum_{j} \delta_{i j k}^{h} Q_{i j}^{h}}{U_{t^{*}}}$. Substituting it for $f$ in Eqs. (4) and (9), respectively. $\overline{T C 1_{t}^{h}}$ and $\overline{T C 2_{t}^{h}}$ can be further expressed as:

$$
\begin{aligned}
\overline{T C 1_{t^{*}}^{h}} & =\frac{M_{k} a x}{\sum_{i} \sum_{j} \delta_{i j k}^{h} Q_{i j}^{h}} U_{t^{*}} \sum_{i}\left[\alpha_{i t^{*}}+S_{t} * W_{i}+B_{i t^{*}}\right. \\
& \left.+D_{i}^{h}\left(\frac{S_{t^{*}}}{V_{t^{*}}}+F_{t^{*}}\right)\right] \\
& \left.+\sum_{i} \sum_{j}\left[\left(G_{i}+\frac{\beta_{i t}^{*}}{R_{i}}+\frac{S_{t^{*}}}{R_{i}}\right)\left(Q_{i j}^{h}+Q_{j i}^{h}\right)\right], \quad(10)\right] \\
\frac{T C 1_{t^{*}}^{h}}{} & \frac{91 H U_{t^{*}}}{2 M a x \sum_{i} \sum_{j} \delta_{i j k}^{h} Q_{i j}^{h}} \sum_{i} \sum_{j} Q_{i j}^{h} \\
& +H \sum_{i} \sum_{j} \sum_{k} Q_{i j}^{h} \delta_{i j k}^{h}\left(W_{k}+\frac{D_{k}^{h}}{V_{t^{*}}}\right) \\
& +\frac{H U_{t^{*}}}{\operatorname{Max}_{k} \sum_{i} \sum_{j} \delta_{i j k}^{h} Q_{i j}^{h}} \sum_{i} \sum_{j} \sum_{k} \sum_{l} \frac{Q_{i j}^{h}}{R_{k}} \delta_{i j k}^{h}\left(Q_{k l}^{h}+Q_{l k}^{h}\right) .
\end{aligned}
$$

Furthermore, $T C 1^{m}\left(Q^{m}\right)$ and $T C 2^{m}\left(Q^{m}\right)$ represent, respectively, the shipping cost and inventory cost on route $m$, which depend on the total flow $Q^{m}$. As shown in Figure 3, $q^{d}$ denote the total flow between the spoke port at origin region and hub at destination region, and $q^{h}$ denote the total flow on the main line between hub at origin and hub at destination region and $q^{s}$ denote the total flow on the feeder line between spoke port at origin region and hub at origin region. Then, when there is total flow $q^{d}$ shipped directly to its destination, total flows on direct line, main line and feeder line will be $q^{d}, q^{h}-q^{d}$, and $q^{s}-q^{d}$, respectively, as shown in Figure 3(a).

Let $T T C 1^{t}$ and $T T C 2^{t}$ denote the total shipping costs and the total inventory costs of feeder line and main line for shipping flow $q^{d}$ through a hub, respectively. If the main line is serviced with the minimum shipping costs, then $T T C 1^{t}$ and $T T C 2^{t}$ can be expressed as

$$
\begin{aligned}
& T T C 1^{t}=\overline{T C 1_{t}^{h} *\left(q^{h}\right)}+T C 1^{s}\left(q^{s}\right), \\
& T T C 2^{t}=\overline{T C 2_{t}^{h} *\left(q^{h}\right)}+T C 2^{s}\left(q^{s}\right) .
\end{aligned}
$$

Where $T C 1^{s}\left(q^{s}\right)$ and $T C 2^{s}\left(q^{s}\right)$ in Eqs. (12) and (13) are the shipping and inventory costs for the feeder line. Moreover, the Pareto optimal solutions for the feeder line can be determined by shipping and inventory cost functions formulated and trade-off relationship between them. The Pareto optimal shipping cost for shipping through a hub is the Pareto optimal shipping cost of the feeder line added by a constant value, $\overline{T C 1_{t^{*}}^{h}\left(q^{h}\right)}$, and the Pareto optimal inventory cost for shipping through a hub is the Pareto optimal inventory cost of the feeder line added by a constant value, $\overline{T C 2_{t}^{h} *\left(q^{h}\right)}$.

Let $T T C 1^{d}$ and $T T C 2^{d}$ denote, respectively, the total shipping costs and the total inventory costs of direct line, main line, and feeder line for shipping flow qd directly. Then, if the main line is serviced with the minimum shipping cost, then $T T C 1^{d}$ and $T T C 2^{d}$ can be expressed as

$$
\begin{aligned}
& T T C 1^{d}=\overline{T C 1_{t^{*}}^{h}\left(q^{h}-q^{d}\right)}+T C 1^{s}\left(q^{s}-q^{d}\right)+T C 1^{d}\left(q^{d}\right), \\
& T T C 2^{d}=\overline{\left.T C 2_{t^{h}} * q^{h}-q^{d}\right)}+T C 2^{s}\left(q^{s}-q^{d}\right)+T C 2^{d}\left(q^{d}\right) .
\end{aligned}
$$

Where $T C 1^{s}\left(q^{s}-q^{d}\right)$ and $T C 2^{s}\left(q^{s}-q^{d}\right)$ are the shipping and inventory costs of the feeder line, respectively; $T C 1^{d}\left(q^{d}\right)$ and $T C 2^{d}\left(q^{d}\right)$ are the shipping and inventory costs of the direct line, respectively. Since there are trade-offs between shipping cost and inventory cost, the Pareto optimal solutions for these two lines can also be determined by the cost functions formulated. Consequently, the Pareto optimal solutions for direct shipping can be determined. They are the Pareto optimal shipping costs of both the feeder line and

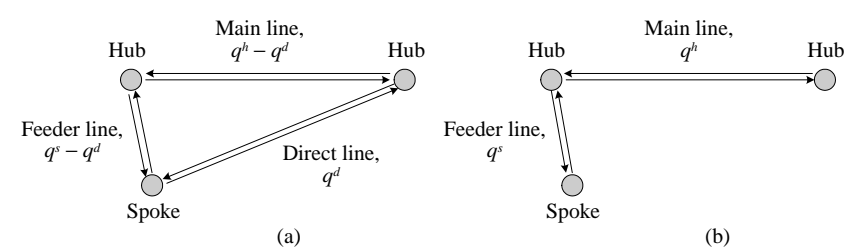

Fig. 3. The total flow on each line: (a) part with direct shipment; (b) all with transshipment. 
the direct line added by a constant value, $\overline{T C 1_{t^{*}}^{h}\left(q^{h}-q^{d}\right)}$, and the Pareto optimal inventory costs of both the feeder line and direct line added by a constant value, $\overline{T C 2^{h}{ }^{*}\left(q^{h}-q^{d}\right)}$.

\section{EXAMPLE}

A Transpacific containership service from Far East to U.S. west coast is considered herein to demonstrate the application of the proposed model. The shipping service is operated by an ocean carrier who provides services using hub-and-spoke networks. The shipping route of main line starts at Kaohsiung, passes Busan, Los Angeles, Busan, Hong Kong, and backs to Kaohsiung, as shown on solid lines of Figure 4. The objective of the example attempts to apply the proposed model to make analyses about routing decisions on whether shipping containers from Manila, a major port in Philippines, to U.S. west coast through hub port, Kaohsiung, or directly to U.S. west coast, as shown in
Figure 4(a) and 4(b), respectively.

Suppose there are five types of ships used by the ocean carrier, and let $T_{i}(i=1 \ldots 5)$ denote the types of ships from $i=1$, the smallest, to $i=5$, the largest. Table 1 shows the capacity, service speed, capital and operating costs, and fuel cost for each type of ship. In addition, port charge on ship $\left(\alpha_{i t}, \beta_{i t}\right)$ and loading/ unloading charges in port, $G_{i}$, are estimated using port charge of Kaohsiung Harbor (Kaohsiung Harbor Bureau. MOTC, ROC [12]). Two-way flows between Kaohsiung and Manila are estimated from data published by Department of Statistics, MOTC, ROC [6], while the others are estimated from the data provided by Institute of Transportation, MOTC, ROC [10]. Besides, the average gross handling rate, $R_{i}$, and the port arrival and departure time, $W_{i}$, are estimated from the vessel arrival/departure time data of Kaohsiung Harbor.

When containers between Manila and U.S. west coast are transshipped through the hub, Kaohsiung, the minimum shipping cost of the main line is $2.6907872 \times$

Table 1. Capacity, service speed, daily capital and operating cost, and fuel cost for each type of ship

\begin{tabular}{|c|c|c|c|c|c|}
\hline Type of ships ${ }^{\mathrm{a}}$ & $\mathrm{T} 1$ & $\mathrm{~T} 2$ & $\mathrm{~T} 3$ & $\mathrm{~T} 4$ & $\mathrm{~T} 5$ \\
\hline Capacity, $U_{t}$ (TEU) & 1,810 & 2,728 & 3,428 & 4,211 & 5,652 \\
\hline Service speed, $V_{t}$ (nautical miles per day) a & 504.0 & 492.0 & 496.8 & 600.0 & 600.0 \\
\hline Daily capital and operating cost, $S_{t}$ (U.S. dollars) ${ }^{\mathrm{b}}$ & 21,940 & 22,865 & 23,571 & 24,360 & 25,813 \\
\hline Fuel cost per nautical mile, $F_{t}$ (U.S. dollars) $^{\mathrm{b}}$ & 15.51 & 20.81 & 24.32 & 23.57 & 29.89 \\
\hline Fuel cost in port, $B_{i t}$ (U.S. dollars) $^{\mathrm{b}}$ & 77.62 & 104.05 & 121.59 & 117.84 & 149.44 \\
\hline
\end{tabular}

${ }^{\text {a }}$ Source: Five types of ships are currently used by Evergreen Marine Corporation, http://www.evergreen-marine.com.

${ }^{\mathrm{b}}$ Source: Wang [20].

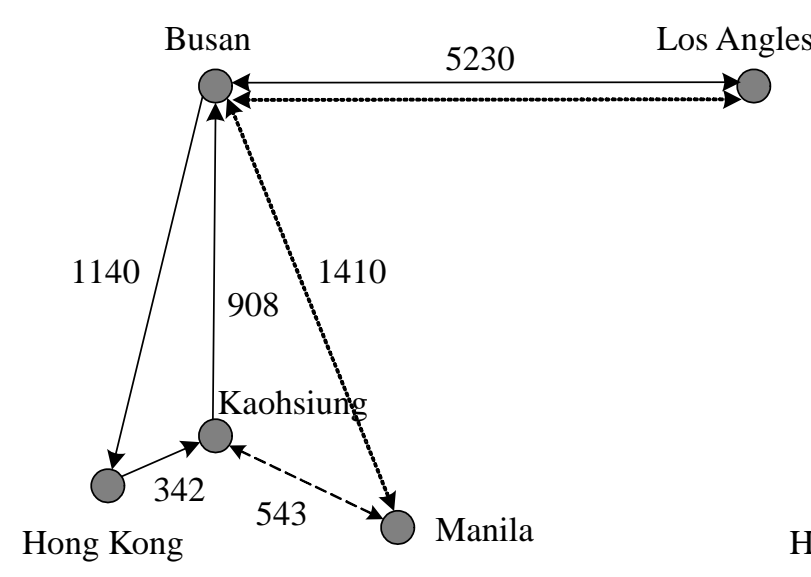

(a)

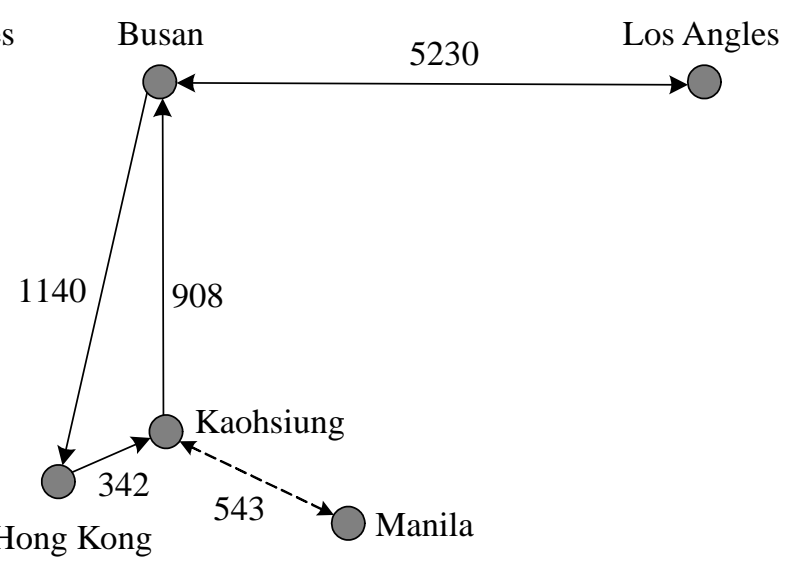

(b)

Source of shipping distance: Caney and Reynolds [2].

Fig. 4. The marine networks: (a) direct shipment; (b) transshipment. (number represent link distance in nautical miles) 
$10^{7}$ U.S. dollars and the corresponding inventory cost of the main line is $7.3117449 \times 10^{7}$ U.S. dollars. In addition, the Pareto optimal solutions of the feeder line are determined using Eqs. (4) and (9), and shown as:

$$
T C 1^{s}=\left\{\begin{array}{l}
2.02778 \times 10^{6}+\frac{2.00142 \times 10^{12}}{T C 2^{s}-452,685} \text { for } 452,685<T C 2^{s} \leq 1.16478 \times 10^{6}, \\
1.97306 \times 10^{6}+\frac{1.8233 \times 10^{12}}{T C 2^{s}-528,446} \text { for } 1.16478 \times 10^{6}<T C 2^{s} \leq 4.50374 \times 10^{6}, \\
1.9892 \times 10^{6}+\frac{2.04908 \times 10^{12}}{T C 2^{S}-539,995} \text { for } 5.17042 \times 10^{6} \leq T C 2^{s} \leq 6.53149 \times 10^{6}, \\
2.02778 \times 10^{6}+\frac{2.00142 \times 10^{12}}{T C 2^{s}-452,685} \text { for } 7.04893 \times 10^{6} \leq T C 2^{s} \leq 9.70128 \times 10^{6} .
\end{array}\right.
$$

The Pareto optimal solutions for routing a shipment through hub port, Kaohsiung, are determined and shown in the objective value space in Figure 5. The optimal ship size for feeder line associated with each Pareto optimal solution is also obtained. There exist three types of ships in the Pareto optimal solutions. The optimal ship size of feeder line is T4, T2 and T1, for three cases that the value of $T T C 2^{t}$ is without constraint or constrained to be lower than $7.36 \times 10^{7} \mathrm{U}$.S. dollars; lower than $8.02 \times 10^{7}$ U.S. dollars; and lower than $7.83 \times 10^{7}$ U.S. dollars, respectively.

On the other hand, when containers between Manila and U.S. west coast are shipped directly, the minimum shipping cost of the main line is $2.500537 \times$ $10^{7}$ U.S. dollars, and the associated inventory cost of the main line is $6.933135 \times 10^{7}$ U.S. dollars. In addition, the Pareto optimal solutions of the feeder line and the direct line are determined using Eqs. (4) and (9), as follows:

$$
T C 1^{s}=\left\{\begin{array}{l}
833,950+\frac{7.45174 \times 10^{11}}{T C 2^{s}-186,713} \text { for } 186,173<T C 2^{s} \leq 515,127, \\
811,440+\frac{6.78855 \times 10^{11}}{T C 2^{s}-217,330} \text { for } 515,127<T C 2^{s} \leq 4.74098 \times 10^{6}, \\
818,083+\frac{7.62918 \times 10^{11}}{T C 2^{s}-222,080} \text { for } 5.54105 \times 10^{6} \leq T C 2^{s} \leq 7.04004 \times 10^{6}, \\
833,950+\frac{7.45174 \times 10^{11}}{T C 2^{s}-186,173} \text { for } 7.94584 \times 10^{6} \leq T C 2^{s} \leq 1.07105 \times 10^{7}, \\
T C 1^{d}=\left\{\begin{array}{l}
1.19383 \times 10^{6}+\frac{1.16014 \times 10^{13}}{T C 2^{d}-2.63641 \times 10^{6}} \text { for } 2.63641 \times 10^{6}<T C 2^{d} \leq 1.02345 \times 10^{7}, \\
1.22347 \times 10^{6}+\frac{1.31551 \times 10^{13}}{T C 2^{d}-2.63641 \times 10^{6}} \text { for } 1.14227 \times 10^{7} \leq T C 2^{d} \leq 1.28346 \times 10^{7} .
\end{array}\right.
\end{array}\right.
$$

The Pareto optimal solutions for routing a shipment directly to U.S. west coast are determined and shown in Figure 6. The optimal ship size for both feeder line and direct line are also obtained and further shown in Table 2.

Figure 7 shows both Pareto optimal solutions for transshipment and direct shipping in one objective value space. For the range of inventory costs between $7.385 \times 10^{7}$ and $8.015 \times 10^{7}$ U.S. dollars, transshipment is preferred, while for others, direct shipping is preferred. Furthermore, the influences of flow on the optimal solution are analyzed. Suppose that two-way flows between Manila and Los Angeles and between Manila and Busan are raised five times, while the others remain the same. Then, the Pareto optimal solutions for both routing a shipment through Kaohsiung and directly to Los Angeles are determined and shown in one objective value space (Figure 8 ). Figure 8 shows that no matter 
Table 2. The optimal ship size for direct shipping

Unit: U.S. dollars

\begin{tabular}{ccc}
\hline The inventory costs for direct shipping & \multicolumn{2}{c}{ Optimal ship size } \\
\cline { 2 - 3 } TTC2 $^{\mathrm{d}}$ & Direct line & Feeder line \\
\hline $\mathrm{TTC}^{\mathrm{d}}<7.36 \times 10^{7}$ & $\mathrm{~T} 4$ & $\mathrm{~T} 4$ \\
$7.36 \times 10^{7}<\mathrm{TTC}^{\mathrm{d}}<8.43 \times 10^{7}$ & $\mathrm{~T} 4$ & $\mathrm{~T} 1$ \\
$8.43 \times 10^{7}<\mathrm{TTC}^{\mathrm{d}}<8.66 \times 10^{7}$ & $\mathrm{~T} 4$ & $\mathrm{~T} 2$ \\
$8.66 \times 10^{7}<\mathrm{TTC}^{\mathrm{d}}<8.69 \times 10^{7}$ & $\mathrm{~T} 5$ & $\mathrm{~T} 1$ \\
$8.69 \times 10^{7}<\mathrm{TTC2}^{\mathrm{d}}<8.92 \times 10^{7}$ & $\mathrm{~T} 5$ & $\mathrm{~T} 2$ \\
$8.92 \times 10^{7}<\mathrm{TTC}^{\mathrm{d}}<10.92 \times 10^{7}$ & $\mathrm{~T} 5$ & $\mathrm{~T} 4$ \\
\hline
\end{tabular}

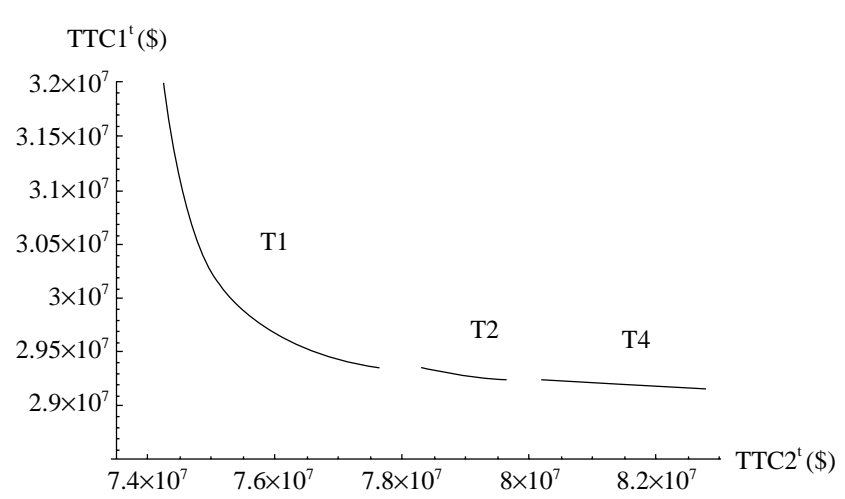

Fig. 5. The Pareto optimal solutions for transshipment.

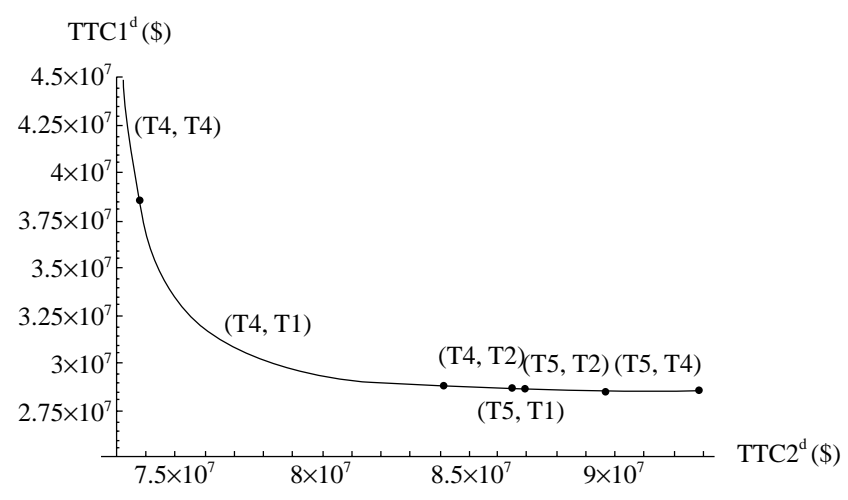

Fig. 6. The Pareto optimal solutions for direct shipping.

what the inventory costs are, the direct shipping is always the optimal routing decision. The result shows that the routing decision tends to ship shipment directly to its destination as container flow between origin and destination ports increases.

\section{CONCLUSION}

This study developed a two-objective model by

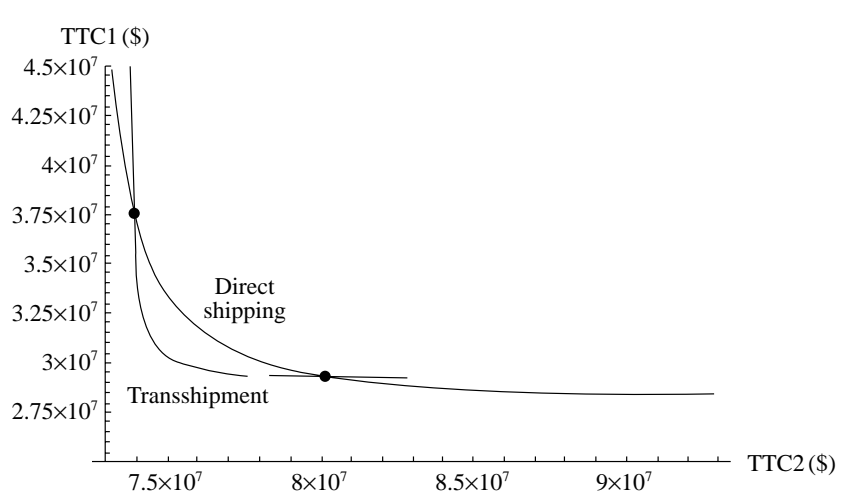

Fig. 7. Comparing Pareto optimal solution between transshipment and direct shipping.

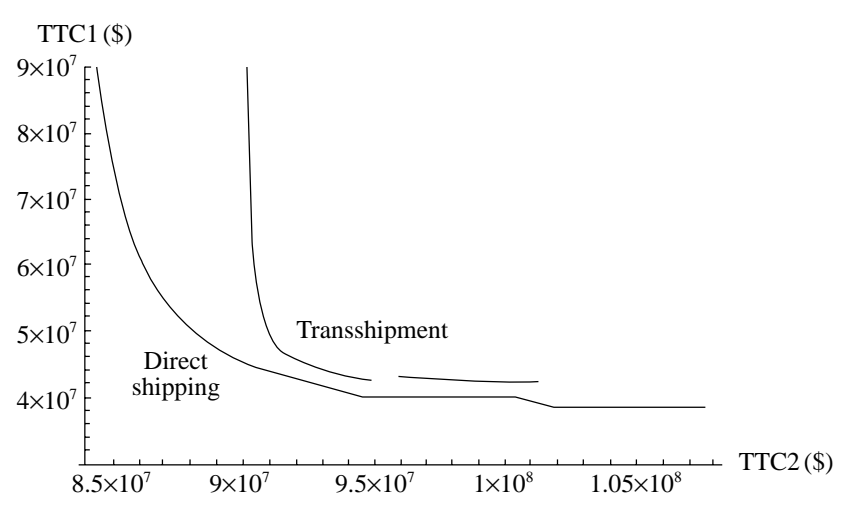

Fig. 8. Pareto optimal solutions for transshipment and direct shipping as flow increases.

individually minimizing shipping costs and inventory costs to decide whether to route a shipment through a hub or directly to its destination. The cost functions formulated herein are flow-dependent. Moreover, the shipping costs include capital and operating cost, fuel cost and port charge, while the inventory costs include waiting time cost and shipping time cost.

Based on a trade-off between shipping cost and 
inventory costs for two types of shipping routes, the Pareto optimal solutions of the two-objective model are determined, and a routing decision can be illustrated and made in objective value space. Finally, the optimal routing, ship size and sailing frequency with respect to each level of inventory cost is shown. The result shows that the optimal routing decision tends to be direct shipping as container flow between origin and destination ports increases.

In summary, this study has demonstrated that the two-objective model could be used to solve the routing decision problem. The two-objective model thus proposed not only provides flexibility for carriers on route decision-making, but also provides a tool to analyze the trade-off between shipping cost and inventory cost.

\section{REFERENCES}

1. Bendall, H.B. and Stent, A.F., "A Scheduling Model for a High Speed Containership Service: A Hub and Spoke Short-Sea Application," Int. J. Marit. Econ., Vol. 3, pp. 262-277 (2001).

2. Caney, R.W. and Reynolds, J.E., Reed's Marine Distance Tables, Thomas Reed Publications, Great Britain (1995).

3. Cho, S.C. and Perakis, A.N., "Optimal Liner Fleet Routing Strategies," Marit. Policy Manage., Vol. 23, No. 3, pp. 249-259 (1996).

4. Cohon, J.L., Multiobjective Programming and Planning, Academic Press, New York (1978).

5. Daganzo, C.F., Logistics System Analysis, SpringerVerlag Press, Berlin, Heidelberg (1991).

6. Department of Statistics, Statistical Abstract of Transportation and Communications 2002 Republic of China, Department of Statistics Publications, Taipei, Taiwan (2003).

7. Hall, R.W., "Direct Versus Terminal Freight Routing on a Network with Concave Costs," Transport. Res. B, Vol. 21, No. 4, pp. 287-298 (1987).

8. Hsu, C.I. and Hsieh, Y.P., "Ship Size and Sailing Frequency Decision-Making for Container Liners," Transport. Pl. J., Vol. 34, No. 2, pp. 211-242 (2005). (In
Chinese)

9. Hsieh, S.H. and Chang, F.R., "Applications of the Huband-Spoke Network Model in Routing Liner Ships," Transport. Pl. J., Vol. 30, No. 4, pp. 871-890 (2001). (In Chinese)

10. Institute of Transportation, A Traffic Forecast Study of Sea Ports in Taiwan, Institute of Transportation Publications, Taipei, Taiwan (1999). (In Chinese)

11. Jansson, J.O. and Shneerson, D., Liner Shipping Economics, Chapman and Hall Ltd, London (1987).

12. Kaohsiung Harbor Bureau, Port of Kaohsiung: Tariff of Port Charges, Kaohsiung Harbor Bureau Publications, Kaohsiung, Taiwan (2002).

13. Mourão, M.C., Pato, M.V., and Paixão, A.C., "Ship Assignment with Hub and Spoke Constraints," Marit. Policy Manage., Vol. 29, No. 2, pp. 135-150 (2001).

14. Powell, B.J. and Perakis, A.N., "Fleet Deployment Optimization for Liner Shipping: an Integer Programming Model," Marit. Policy Manage., Vol. 24, No. 2, pp. 183192 (1997).

15. Rana, K. and Vickson, R.G., "A Model and Solution Algorithm for Optimal Routing of a Time-Chartered Containership," Transport. Sci., Vol. 22, No. 2, pp. 8395 (1988).

16. Robinson, R., "Asian Hub/Feeder Nets: the Dynamics of Restructuring," Marit. Policy Manage., Vol. 25, No. 1, pp. 21-40 (1998).

17. Ronen, D., "Cargo Ships Routing and Scheduling: Survey of Models and Problems," Eur. J. Oper. Res., Vol. 12, pp. 119-126 (1983).

18. Ronen, D., "Ship Scheduling: The Last Decade," Eur. J. Oper. Res., Vol. 71, pp. 325-333 (1993).

19. Sambracos, E., Paravantis, J.A., Tarantilis, C.D., and Kiranoudis, C.T., "Dispatching of Small Containers via Coastal Freight Liners: The Case of the Aegean Sea," Eur. J. Oper. Res., Vol. 152, pp. 365-381 (2004).

20. Wang, H.J., "Container Transshipment Analysis for the Port of Kaohsiung as a Transshipment Center," Master Thesis, Department of Shipping and Transportation Management, National Taiwan Ocean University (1998). (In Chinese) 